\title{
La importancia de los referentes culturales \\ en la enseñanza de la pintura virreinal a estudiantes extranjeros*
}

\author{
Oscar \\ Flores Flores \\ CEPE-UNAM
}

\begin{abstract}
"Tiene algo de inquietante el hecho de que el arte japonés sea tan bello y, al mismo tiempo tan absolutamente distinto del nuestro, tanto para hacer pensar por un instante si no es mejor. Pero lo sea o no, debemos seguir nuestro camino, pues nuestras tradiciones y nuestra práctica no nos conducen a representar la natural eza como los japoneses".
\end{abstract}

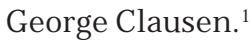

\section{INTRODUCCIÓN}

Uno de los problemas más frecuentes en la enseñanza de la pintura virreinal de la Nueva España a los estudiantes extranjeros, es la falta de referentes culturales, particularmente en el caso de los estudiantes orientales, quienes no sól o se enfrentan con el problema de aprender una lengua occidental radical mente diferente a la propia, sino que también, en la mayoría de los casos, carecen de elementos relacionados con distintos aspectos de la cultura occidental, los cual es les permitirían comprender significativamente la pintura producida en Europa y América durante los siglos XVI al XVIII.

En este trabajo se abordará brevemente dicha problemática y se expondrán al gunos de los recursos metodológi cos que he desarrollado para poder preparar el curso, con el objetivo primordial de que los al umnos puedan entender conceptos y procesos fundamentales de la historia del arte occidental en general y de la historia de la pintura virreinal novohispana en particular.
Quiero agradecer a las siguientes personas: a los maestros Rosario Gutiérrez Haces y a José Carlos Escobar Hernández, quienes no solamente mostraron interés en la realización de este trabajo, sino que generosamente compartieron conmigo su experiencia docente en la enseñanza del español a extranjeros, lo cual fue de gran ayuda en la elaboración de este artículo; a Roberto Muñoz Vázquez quien llevó a cabo el desarrollo del CD interactivo de la propuesta didáctica que explico en estas páginas y finalmente a Ligia Fernández Flores por sus comentarios y observaciones, así como por la revisión final.

1 Fragmento de una conferencia pronunciada por este pintor, en la Royal Academy de Londres en 1904, citado por E.H. Gombrich "El primitivismo y lo primitivo" en Richard 
Woodfeld. Gombrich

Esencial, Madrid, Debate, 1997, p. 320.

2 Dichas semejanzas tienen sus orígenes en los temas afines que son recurrentes en el arte occidental (representaciones de imágenes religiosas y temas de la mitología clásica por citar sólo dos ejemplos); con modelos comunes (como es el caso de muchas pinturas europeas y americanas que se basan en grabados de obras de los grandes maestros como Rafael, Tiziano y Rubens) y por supuesto por pertenecer a un mismo estilo artístico (Manierismo, Barroco, Neoclasicismo). Un ejemplo concreto de esta problemática lo tenemos en las imágenes que ilustran la siguiente página, en donde se puede apreciar la pintura realizada por el artista holandés Abraham Bloemaert en 1612, misma que fue grabada seis años después por Boetius a Bolswert en una estampa que alcanzó una enorme difusión, tanto en Europa como en América, como se puede apreciar en el gran número de obras que retoman este grabado, siendo un claro ejemplo la pintura del artista novohispano José Juárez, quien en su composición retomó literalmente la parte superior de la pintura de Bloemaert.

Para mayor información sobre la difusión de dicha obra, a través de la versión grabada de Bolswert. Vid., Benito Navarrete Prieto, La pintura andaluza del siglo XVII y sus fuentes grabadas, Madrid, Fundación de Apoyo a la Historia del Arte Hispánico, 1998; concretamente el capítulo VIII "Los grabadores de composiciones de Abraham Bloemaert", pp. 161-180.

\section{Problemática}

Desde hace poco más de tres años he impartido en el Centro de Enseñanza para Extranjeros (CEPE), de la Universi dad Nacional Autónoma de México (UNAM), la clase La pintura virreinal en la Nueva España y a lo largo de todo este tiempo se han inscrito en el curso alumnos mexicanos y extranjeros de diversas nacional idades. En ocasiones he tenido grupos en donde únicamente han asistido al umnos de nuestro país, en otras han preval ecido los extranjeros o bien han sido grupos mixtos; pero en la mayoría de los casos han predominado los estudiantes procedentes del Lejano Oriente particularmente de Corea, China y J apón, circunstancia que ha condicionado de manera significativa la forma en que preparo e imparto la clase.

Todas las personas que nos hemos dedicado a la docencia sabemos los requerimientos que debe tener un programa de curso (temario, objetivos, contenidos, metodología, bibliografía) sin embargo, por experiencia también sabemos, que este "programa ideal" raras veces puede cumplirse debido principalmentea diversos factores tales como la duración del curso, la riqueza de los materialesy en este caso concreto el tipo de alumnos, sus intereses particulares y la manera en que entienden y asi milan los conteni dos del curso; por lo que en la práctica hemos comprobado que el docente tiene que adecuarse a los factores mencionados, así como tener el compromiso académico de modificar ese curso con base en las dudas e inquietudes de sus al umnos. Acorde con lo anterior, puedo decir que el "programa ideal" de mi clase ha tenido que considerar no sólo dichos factores, sino también las limitantes lingüísticas y especial mente la fal ta de referentes culturales de los alumnos.

En efecto, cuando los alumnos oriental es observan por primera vez representaciones pictóricas de la época virreinal en México, por una parte suelen sorprenderse por las grandes "similitudes" que tienen estas pinturas con las realizadas en Europa durante esa misma época (siglos XVI al XVIII) ${ }^{2}$ y por otra tienen problemas para entender el lenguaje artístico de Occidente. 


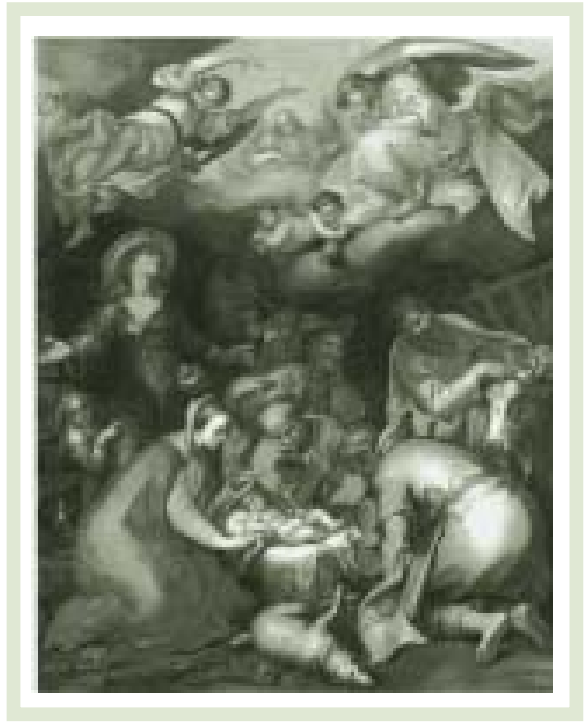

Abraham Bloemaert, (1564-1651)

Adoración de los pastores, 1612

Museo del Louvre

Paris, Francia.
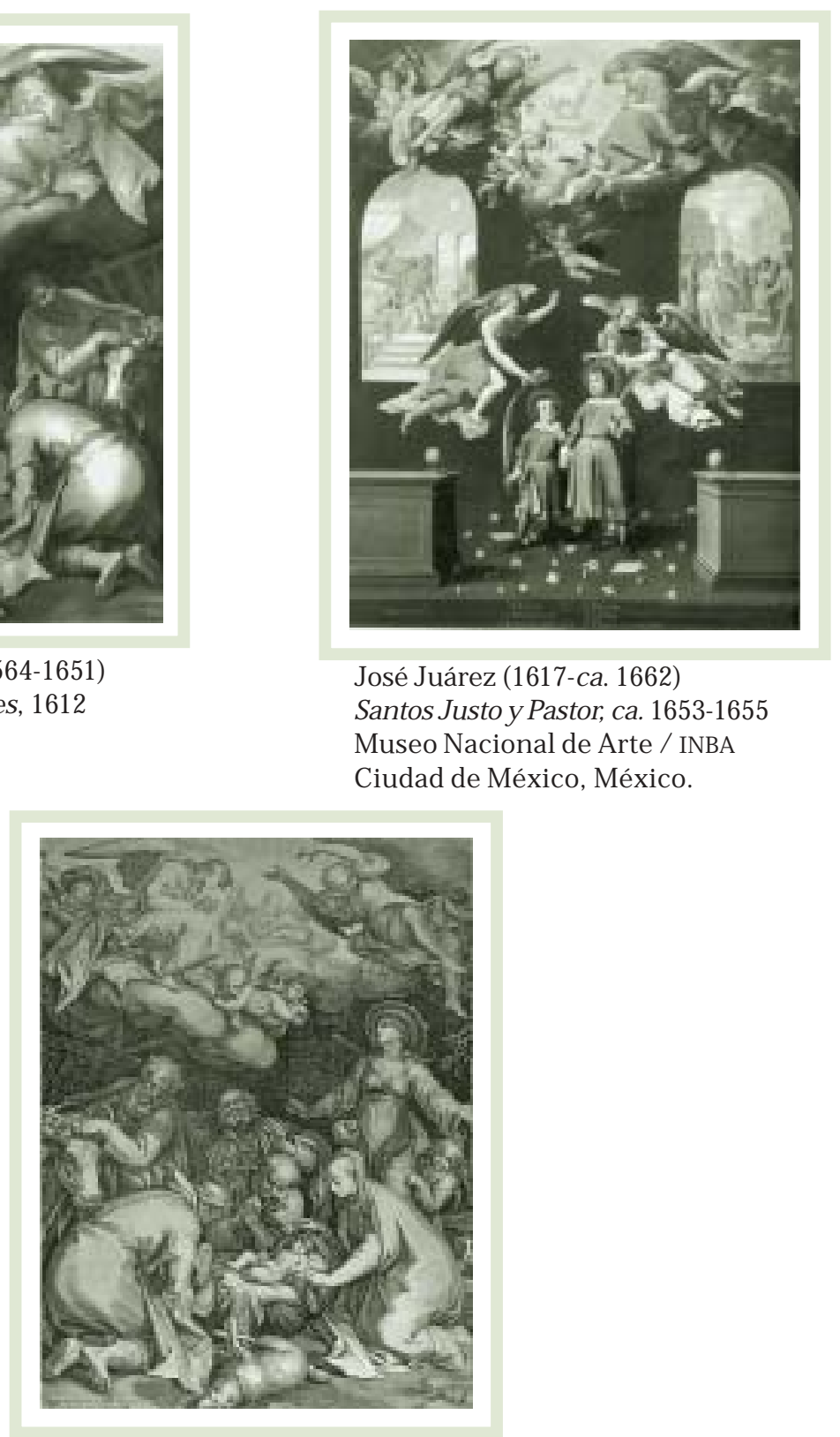

Boetius Adams Bol swert (1580-1633)

Adoración de los pastores, 1618

Grabado sobre composición de Abraham Bloemaert. 
Dicha sorpresa obedece principal menteal desconocimiento que se tiene no sólo en Oriente, sino también en muchos países occidentales sobre el arte mexicano, el cual suele restringirse general mente al arte prehispánico (básicamente el relacionado con las culturas maya y mexica) y a la pintura de la primera mitad del siglo XX (concretamente los muralistas Diego Rivera, J osé Clemente Orozco y David Alfaro Siqueiros y en fechas relativamente recientes Frida Kahlo), por lo que desafortunadamente el arte virreinal y el del siglo XIX, suelen verse como una extensión poco original del arte europeo. Esta situación se resuelve en el aula cuando estudiamos el contexto histórico y cultural en el cual se produjeron las manifestaciones artísticas virreinales, poniendo especial énfasis en explicar el papel que tuvo el virreinato de la Nueva España como parte del Imperio Español y por consi guiente del mundo occidental; no obstante, la comprensión de su lenguaje artístico es un problema mucho más complejo el cual está rel acionado principal mente con los referentes culturales que tienen los alumnos y por consiguiente en su dificultad por comprender lenguajes (en este caso visuales) diferentes a los suyos.

Retomando lo anterior, podemos decir que un aspecto fundamental en el proceso de enseñanza-aprendizajees la transmisión del conocimiento, el cual se puede realizar de muy diversas maneras dependiendo de ciertos factores ya señal ados anteriormente, aunque en el caso que nos ocupa, destacan los contenidos del programay los recursos didácticos que hemos tenido que desarrollar, con el objetivo de fomentar el interés del alumno en los temas del curso y propiciar también la adquisición del conocimiento.

Con respecto al primer punto, ya he mencionado que prácticamentedesdeel primer hasta el último curso quehe impartido, ha sido una constante la presencia de al umnos orientales, quienes en la mayoría de los casos han tenido las mismas dudas y por consiguiente han expresado preguntas similares: ¿qué es un ángel?, ¿qué es la Santísima Trinidad?, ¿por qué hay muchos tipos de cristianos y en qué son diferentes?, ¿qué es el mundo clásico?, ¿qué es la Edad Media?, ¿qué es el Renacimiento?, cuando se refiere a Miguel Ángel ¿está hablando de Miguel Ángel de 
Quevedo?, ${ }^{3}$ ¿qué es Flandes?, ¿por qué si estamos en México usted se refiere al país como Nueva España?, ¿qué es Mesoamérica?, etcétera. Como se puede apreciar, si exceptuamos las últimas dos preguntas que se refieren a la Historia de México, todas las demás están relacionadas con temas importantes de la Historia Universal, no obstante, esta afirmación debe ser matizada, ya que si bien es cierto que desde el punto de vista eurocéntrico estos personajes, zonas geográficas o periodos históricos, son muy significativos, para un estudiante oriental que procede de una parte del mundo con parámetros culturales diferentes, en la mayoría de los casos dichos temas suelen resultarle total mente ajenos.

Esto se debe principal mente, a que cuando se imparten asignaturas como Historia, Historia del Arte o Historia de la Cultura, generalmente se hace con un criterio cronológico, en donde el punto de referencia es el nacimiento de Cristo; de esta manera, nuestra "Iínea del tiempo" parte de este suceso para dividir los acontecimientos en periodos históricos relativamente bien diferenciados (Prehistoria, Antigüedad, Edad Media, Renacimiento, etcétera). Sin embargo, es necesario aclarar que dicha periodización consi dera básicamente la historia de Occidente, pues rara vez se hace referencia a otras partes del mundo y cuando dichas referencias existen, casi siempre se incluyen por su relación con un proceso o acontecimiento vinculado con el mundo europeo.

En este mismo sentido, estarían la mayor parte de los manual es de Historia del Arte, en donde general mente se aborda su estudio como una mera sucesión de estilos artísticos que corresponden a los periodos históricos a los cual es hemos hecho al usión; de esta manera, Ia Historia del Arte, es más bien "la historia del arte occidental", ya que si exceptuamos el arte de las civilizaciones antiguas (Mesopotamia, Egipto, Cercano Oriente, India y China) las manifestaciones artísticas de otras regiones como la América Precolombina, Australia y África, suelen ser tratadas desde un punto de vista antropológico y sólo en fechas relativamente recientes, es que empiezan a ser incluidas en dichos manual es en un capítulo titulado por lo general "Otras culturas". ${ }^{4}$ De igual forma, el arte producido en los antiguos territorios que formaron parte de los
3 Miguel Ángel de Quevedo (1856-1946), destacado ingeniero mexicano que como parte fundamental de su labor profesional promovió la reforestación en gran escala a lo largo de todo el país. El hecho de que los estudiantes tengan presente su nombre, obedece a que así se llama la estación del metro más cercana a las instalaciones del CEPE, por lo que es un punto de referencia obligado para la mayor parte de los alumnos, quienes además de estudiar, viven en el mismo perímetro en donde se ubican el campus universitario y la estación aludida.

4 Un ejemplo representativo de este punto de vista eurocéntrico, lo tenemos en el primer capítulo de una de las obras generales más connotadas del siglo XX; en dicho capítulo cuyo título es "Extraños comienzos. Los pueblos prehistóricos y primitivos; la América antigua", se explican los inicios del arte a través del análisis de pinturas rupestres, escultura y cerámica precolombina, bronces africanos y objetos ceremoniales de las llamadas culturas tradicionales, en este caso, procedentes de Alaska, Nueva Zelanda, Tahití y Nueva Guinea. Vid. Ernest $\mathrm{H}$. Gombrich, Historia del Arte, Madrid, Alianza, 1990, (Alianza Forma, 5), pp. 19-30. 
5 En el caso del arte de la América virreinal en general y de la Nueva España en particular, este interés se vio incrementado a partir de las grandes celebraciones que se llevaron a cabo en Europa y América en 1992, para conmemorar el V Centenario del Descubrimiento de América; es así, que en los últimos años se han realizado grandes exposiciones en donde han privado diversos criterios, aunque puede decirse que han tenido como común denominador el situar el arte virreinal dentro de un contexto cultural más amplio.

6 Peter Burke, grandes imperios europeos durante los siglos XVI al XVIII, suele ser visto como una extensión —casi siempre carente de original idad- de las distintas escuel as artísticas de Europa y sólo recientemente también empieza a ser revaIorado. $^{5}$

Asimismo, la nueva actitud que tienen los historiadores de la cultura y el arte se encuentra relacionado con la "idea del Otro", es decir "[...] la aparición de la preocupación por la identidad cultural y los encuentros culturales, [constituye] un ejemplo más de las numerosas preocupaciones actuales, como por ejemplo, el debate en torno al multiculturalismo, que permite a los estudiosos plantear nuevas cuestiones acerca del pasado", 6 en este sentido, podemos decir que los estudiantes extranjeros que asisten a una institución que tiene una oferta académica como la de nuestro Centro, conforman esa comunidad multicultural a la que hace referencia la cita anterior, por lo que de manera anál oga creemos también que los docentes que enseñan español como segunda lengua y por supuesto los que impartimos otras disciplinas humanísticas como la Historia del Arte, debemos tener presentela diversidad cultural que impera en nuestros sal ones de clase, ya que solamente al tomar real mente conciencia de la diversidad lingüística y cultural de nuestros al umnos, podremos entonces transmitir de manera adecuada los contenidos de nuestros respectivos programas.

Acorde con lo anterior, consideramos también que la relación lenguaje-cultura es fundamental ya que " $L a$ cultura es indispensable para que nuestros estudiantes puedan 'entender, actuar e interactuar' (Miquel y Sans, 1992) en español y desarrollar plenamente su competencia comunicativa." Por ello, para poder propiciar dichas habilidades, es fundamental que consideremos sus referentes culturales, pues no hay que olvidar que a partir de ellos, los estudiantes realizan sus respectivas interpretaciones y asociaciones del medio en donde están inmersos, (Ias cual es podrán variar de manera significativa dependiendo del país de origen del estudiante), incluyendo también los diversos aspectos relacionados con la vida cotidiana y por supuesto con la comprensión de los distintos contenidos académi cos de los programas de lengua y cultura que se imparte en las aulas. 
Esta problemática debe propiciar que el docente busque puntos de referencia entre el tema que se estudia en clase y la cul tura del estudiante, ya que a través de temas y procesos análogos, el alumno puede hacer mayores inferencias que redundarán en una mayor comprensión de los contenidos del curso. Así por ejemplo, cuando en la clase estudiamos un tema concreto, en este caso, las pinturas murales del ex convento agustino de San Miguel Arcángel en Itzmiquil pan que fueron realizadas en el siglo XVI, por artistas indígenas en una zona de frontera entre la antigua Mesoamérica y Aridoamérica, (la primera considerada como una zona de "al ta cultura" y la segunda habitada por pueblos nómadas a los que se les denominaba de manera genérica como chichimecas), utilizo como punto de referencia el caso del I mperio Romano y los puebl os germánicos (denominados bárbaros por los romanos) si se trata de estudiantes occidentales y en el caso de los al umnos procedentes de los países del Lejano Oriente, hago referencia a la antigua China y su relación con los mongoles, de tal forma que en ambos casos los ejemplos son lo suficientemente claros para que los estudiantes entiendan la problemática relacionada con las pinturas indígenas que estamos estudiando.

Otro ejemplo empleado continuamente en la clase, responde a una de las preguntas más recurrentes de los estudiantes asiáticos: ¿por qué el mundo clásico es tan importante para la cultura occidental? Antes de dar una respuesta amplia a esta pregunta tan compleja, suelo decirles que Grecia y Roma son para Occidente lo que China es para el Lejano Oriente, con lo que rara vez los estudiantes de dicha región suelen pedir que se les amplíe la respuesta, pues ellos son conscientes que una gran cantidad de los el ementos culturales que consideran como propios, tuvieron su origen en la antigua China y en este sentido, basta recordar solamente un elemento paradigmático que ilustra muy bien esta relación tan estrecha entre las culturas de dicha región: el Hanzi (conjunto de caracteres pictográficos e ideográficos en que se fundamenta la escritura china) influyó notablemente en la formación del Kandjy japones y en menor medida el han-gl coreano. 
8 A este respecto, es conveniente mencionar que "[...] los miembros de una cultura no son conscientes de la relatividad de esa cultura. Todo miembro de una cultura que no haya hecho un distanciamiento $\mathrm{y} /$ o de mestizaje la percibe y la vive como universal $y$, por tanto, el comportamiento distinto del otro aparece como intencionado y transgresor, cuando, en realidad, a lo único que responde es a un automatismo que le hace reproducir sus pautas culturales que, a su vez, vive como universales" Lourdes Miquel. "el choque intercultural: reflexiones y recursos para el trabajo en el aula" en Carabela. La enseñanza del español comolengua extranjera con fines específicos, Madrid, Sociedad General Española de Librería, S.A.,1999, p. 33. Segunda etapa, no. 45 , febrero 1999, (Metodología y didáctica del español como lengua extranjera. Orientaciones y actividades para la clase).

9 Con relación a la imagen que tienen los estudiantes del Lejano Oriente acerca de la cultura del mundo hispánico, remitimos a los siguientes estudios en donde se incluyen encuestas que nos relevan aspectos interesantes de la mentalidad oriental: ChonWook Park, "La situación actual de la enseñanza de la cultura hispánica en las clases universitarias en Corea" en Ángela Celis y José Ramón Heredia, op. cit., pp.341-348; Virginia Meza Hernández, "La imagen de México entre estudiantes japoneses (1972-1989)" en Vera Valdés Lakowsky (coord.) Tiempo, Historiay enseñanza. Acercamiento a la metodología del historiador y al estudio del
Cabe mencionar que los dos procesos a los cuales nos hemos referido anteriormente (comprensión e interpretación), en la mayoría de los casos se realizan de manera inconsciente, ya que la forma en la que el alumno perci be la realidad depende básicamente de su grado de estudios y el nivel socioeconómico al que pertenece (ambos aspectos por demás importantes), aunque también el papel que tiene la tradición cultural esfundamental en la forma en la que el estudiante se relaciona con la sociedad en la cual está inmerso, por consiguiente, dicha interpretación no puede ser concl uyente, por lo que es primordial que en la clase se aborde el problema de la relatividad del conocimiento explicando que éste está determinado cultural mente y está siempre condicionado por los conceptos de tiempo y espacio. ${ }^{8}$

Por ello, el maestro debe estar atento a este problema, ya que como hemos visto, en muchos aspectos los referentes culturales condicionan el entendimiento entre una cultura y otra, y en consecuencia, no se deben dar por supuesto conocimientos que, en la mayoría de los casos, el estudiante no tiene, particularmente si se trata de estudiantes pertenecientes a culturas tan diferentes a la nuestra. ${ }^{9}$

Dentro de este contexto, podemos analizar el problema de la enseñanza de la pintura virreinal de la Nueva España a los estudiantes extranjeros como un proceso complejo, ya que independientemente del interés que tenga el alumno por conocer algún aspecto de la cultura mexicana, debemos reconocer que cuando se inscriben a clases como la que imparto, generalmente lo hacen para complementar su aprendizaje del español, ya que son conscientes que el estudiar una clase de "cultura" no sólo les dará elementos para ampliar su conocimiento sobre la sociedad en la que están inmersos, sino que también les ayudará a desarrollar diversas habilidades lingüísticas, como la comprensión auditiva, la expresión oral, la comprensión de lectura y la redacción, por lo que a los docentes que en este caso impartimos clases de Historia del Arte, esta circunstancia representa una oportunidad única en la que podemos contribuir de manera significativa a la formación del alumno, tanto por nuestra aportación indirecta al aprendizaje del español como segunda len- 
gua, como por los contenidos culturales específicos de nuestra clase.

Este aspecto debe resaltarse, ya que con base en la revisión de diversos estudios en donde se aborda la relación lenguaje-cultura y por la experiencia directa con los alumnos, sabemos que en los cursos de español como lengua extranjera, los temas cultural es que se imparten general mente hacen referencia a los usos y costumbres de la cultura nativa o en al gunos casos se emplean temas relacionados con el arte, como ejemplos concretos para estudiar problemas gramatical es, para fomentar la lectura y redacción, como tema de conversación o para enriquecer el vocabulario; ${ }^{10}$ todo lo anterior es parte fundamental del proceso de enseñanza-aprendizaje, aunque creemos que nuestro papel como maestros de Historia del Arte debe ser ante todo promover el conocimiento de nuestra área de estudio entre los estudiantes extranjeros, y para ello, debemos desarrollar nuevos métodos y estrategi as de enseñanza adecuadas a nuestros grupos interculturales.

Ahora bien, con relación a los recursos didácticos que hemos tenido que desarrollar, mencionaré sólo un ejemplo en donde he tratado de subsanar el problema de la falta de referentes culturales.

\section{RECURSOS DIDÁCTICOS}

Como ya hemos señalado reiteradamente a lo largo de este artículo, el hecho de que mayoritariamente se inscriban al umnos oriental es a nuestra clase, ha condicionado la forma en que ésta se imparte, ya que son ellos quienes presentan mayores diferencias con nuestros parámetros culturales, especial mente en temas relacionados con la religión, el idioma, la escritura y el arte; por ello, independientemente que el tema de la clase sea el de la pintura novohispana, hemos considerado pertinente realizar una introducción muy general al arte occidental, desdela Prehistoria hasta las Vanguardias del siglo XX, teniendo como hilo conductor el tema "EI naturalismo en la pintura", ya que a través del estudio de la pintura europea y su comparación con la producida en otras regiones, el al um-
Este de Asia. Homenaje a Lothar Knauth, México, Universidad Nacional Autónoma de México / Facultad de Filosofía y Letras, 2004, (Jornadas), pp. 189-199. Un ejemplo muy ilustrativo de los resultados de la encuesta que se incluye en este artículo es la existencia del estereotipo de nuestro país, "México y los mexicanos aparecen asociados con los consabidos: sombreros, toros, sol, pirámides y cactus. Más recientemente con tacos $y$ comida picante". p. 190. No obstante también es significativo que en ambos casos los estudiantes señalaron a la historia y la cultura entre sus intereses principales para aprender español.

$10 \mathrm{Ma}$. Carmen Alonso Morales, "La pintura en el aula de L2. Teoría y práctica" en Ángela Celis y José Ramón Heredia op. cit., p.117-122 y Rosalie Sitman. "A propósito de la paleta y el pincel..." Ibid, pp. 429-439. 
11 La decisión de escoger el tema de "El naturalismo", se debe a que independientemente de que otras civilizaciones hayan utilizado esta forma de representación artística para fines diversos, podemos decir que desde la antigüedad, el naturalismo ha sido una de las preocupaciones más importantes del arte occidental, como lo podemos apreciar en los textos de autores clásicos como Plinio o Vitruvio quienes al describir el arte de los "antiguos" alababan aquellas pinturas que estaban "copiadas al natural", ya que de acuerdo con sus ideas "No deben aprobarse las pinturas que no sean imitación de lo verdadero [...]" v.g. Marco Vitruvio Polión, Los diez libros de arquitectura, Madrid, Akal, 1992, (Fuentes de arte, 2), pp.178-181. De esta manera, podemos decir que independientemente de la forma en que el naturalismo ha sido entendido y por consiguiente representado a lo largo de la Historia de Occidente, su utilización ha sido una constante fundamental en la " [...] la cadena de una tradición que todavía relaciona el arte de nuestros propios días con el de la época de las pirámides". Gombrich, op. cit., p. 474.

12 Rahll, Dietrich, "Por una ampliación del concepto de "enfoque comunicativo" en Estudios de Lingüística Aplicada, México, Universidad Nacional Autónoma de México / Centro de Enseñanza de Lenguas Extranjeras, año 7 , núm., 9 , julio de 1989 , p. 30. no puede entender conceptos fundamentales de la H istoria del Arte, tales como perspectiva, volumen, color, dibujo, representación, naturalismo, real ismo, arte figurativo, arte abstracto, etcétera, conceptos cuya comprensión es indispensable para poder estudiar adecuadamente el tema concreto del arte virreinal de la Nueva España. ${ }^{11}$

Es así, que la comparación ha sido un recurso muy importante a lo largo de mis clases, ya que el establecer anal ogías y señalar coincidencias y sobre todo diferencias entre las manifestaciones artísticas de diversas épocas y culturas, ha sido fundamental en la forma en que mis al umnos se han acercado a la historia del arte occidental en general y al de la Nueva España en particular, ya que en muchos casos "En el diálogo entre las culturas, lo interesante no son necesariamente las semejanzas, sino las diferencias; la alteridad; la perspectiva desde otra posición; las tradiciones, costumbres y valores diferentes [...] abrir el horizonte, sobre todo a nivel superior incluye una dimensión histórica y reflexión sobre lo ajeno",12 a este respecto, puedo decir que se ha motivado la reflexión del alumno hacia este tipo de problemas, a través de ejemplos concretos en donde se pueden analizar las características pictóricas de obras pertenecientes a distintas tradiciones artísticas.

De esta manera, al observar las pinturas los estudiantes realizan un primer acercamiento a algunas obras maestras de la Historia del Arte Universal señalando las coincidencias y los exhorto a descubrir particularmente las diferencias entre unas y otras, las cuales son percibidas muy fáci lmente por los al umnos ya que procuro que estas sean muy evidentes.

Ahora bien, este ejercicio al que podemos Ilamarle "primera lectura de las imágenes" sería al go superficial si no se tuviera el cuidado de dirigir adecuadamente la discusión en torno a las pinturas que se están estudiando, por lo que siempre procuro inducirlos no sólo a que señalen las diferencias, sino que los exhorto a que reflexionen en torno a las opiniones que han expresado, de modo que puedan sacar concl usiones que nos den la pauta para pasar a un segundo nivel de lectura mucho más complejo.

En este sentido, una vez que se han comparado y detectado las características que distinguen a una obra de arte 
de otra, pasamos a una segunda etapa de análisis y reflexión en dondela interpretación es nuestro objetivo central; a este respecto, “Diversos procedimientos comparativos, por ejemplo la confrontación del objeto investigado con otros ligados a él por al guna semejanza real o aparente, permiten detectar más agudamente sus peculiaridades o los parentescos internos. Se trata esencialmente de un proceso de diferenciación, y la comparación es uno de los medios más eficaces para acelerarlo [... $]^{\prime \prime}{ }^{13}$

Un ejemplo concreto de esta forma de análisis lo tenemos en la representación del paisaje, un género pictórico que junto al retrato es probablemente la forma de representación naturalista por excelencia, no obstante, de acuerdo con lo expresado a lo largo de estas líneas, este criterio lo podemos aplicar solamente a pinturas occidentales, pues cuando comparamos cuadros que comparten la misma temática (aunque sea de manera incidental)
$13 \mathrm{Al}$ respecto, el mismo autor continúa diciendo que "Hay ciencias, como el derecho comparado o la lingüística, para las cuales la comparación se convertido en un atributo de la disciplina. En cada caso, la función de la comparación es radicalmente distinta, pero en todos, incluso en el nuestro, se reconoce el papel principal que desempeñacomo método heurístico". Ibidem.

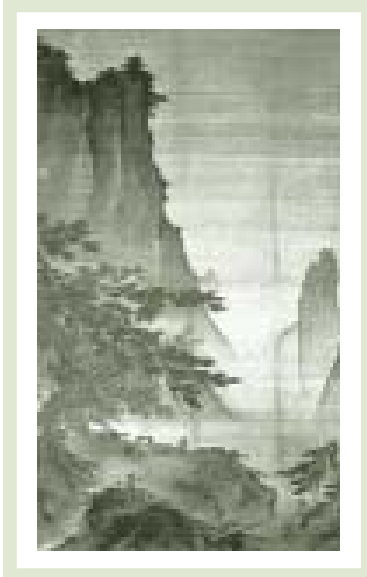

MaYuan (ca. 1190-ca. 1225) Paisaje a la luz de la luna, ca. $\mathrm{s} / \mathrm{f}$

Museo Nacional del

Palacio Taipe, Taiwan.

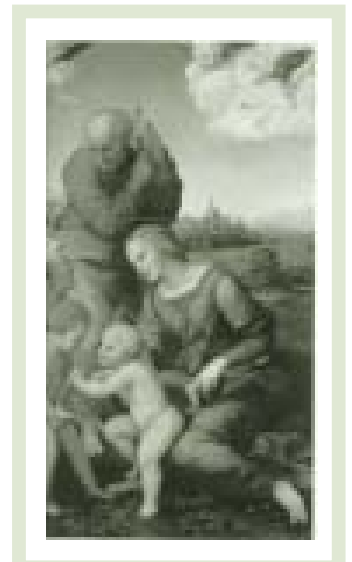

Rafael Sanzio (1483-1520)

Sagrada Familia

Canigiani, 1513

AltePinacotek

Munich, Alemania.

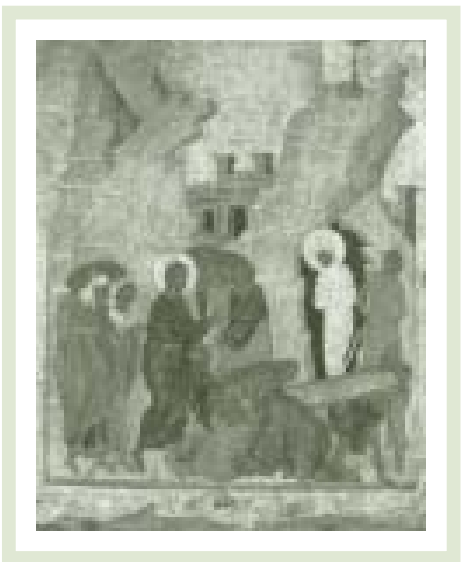

Anónimo

Resurrección de Lázaro, siglo xv Museo Histórico Moscú, Rusia. 
14 En este sentido, podemos decir que "La diferencia es de percepción y propósito. El artista griego deseaba representar una realidad material de maneras naturalistas; el artista egipcio le interesaba captar aspectos universalmente representativos del mundo de maneras estilizadas", vid. Dani Cavallaro y Carline Vago-Hughes, Historia del arte para principiantes, Buenos Aires, Era Naciente, 2000, (Para Principiantes, 69), p. 21. Estrechamente relacionado con lo anterior, estos también autores señalan: "El arte, la literatura y la mente humana no reflejan la realidad sino que la representan según códigos y convenciones conscientes, semi inconscientes e inconscientes. Eso está demostrado porel hecho de que no todas las culturas aceptan el realismo como su modo de expresión dominante". Ibid., p. 6.

15 Con relación a este problema, creemos conveniente considerar la siguiente información: "En la lengua china el término paisaje y su concepto, se forma a partir de dos caracteres: shan, montaña y shui, agua. El paisaje como principal género pictórico se constituye como la representación de las montañas y el agua, los dos elementos que definen el universo. A través de ellos el artista representa espiritualmente al ser humano, siendo su presencia imperceptible, sutil, como un espectador que participa de las transformaciones de la naturaleza. El paisaje representado por los pintores no es realista, ni naturalista, sino espiritual y simbólico. Por ello el artista no se entretiene intentando conseguir pero que pertenecen a otras tradiciones, inmediatamente se aprecian las diferencias.

Esto se debe a que el mundo occidental tiene una antigua tradición natural ista cuyos orígenes se remontan al mundo clásico, por lo queen términos general es esta pintura es imitativa, mientras que en otras tradiciones como en el antiguo Egipto o en Mesoamérica, es selectiva, es decir, la natural eza no es representada de una manera "real ista", sino que los artistas sel eccionan únicamente aquellos elementos que consideran más característicos del objeto o escena que se quiere pintar, ${ }^{14}$ de manera anál oga, cuando anal izamos una pintura china debemos tener presente que lo que nosotros como espectadores occidentales vemos como un paisaje, o en el mejor de los casos como una al egoría, en real idad es una muestra pictórica de una concepción absol utamente distinta de la vida y del mundo..$^{15}$ Otro ejemplo que coincide en ciertos aspectos con esta forma de pensamiento, pero que pertenece al ámbito europeo, es el de los íconos de la I glesia Ortodoxa de Oriente, en donde las representaciones divinas y humanas se hacen con base en model os ideales preestablecidos que garantizan la unidad doctrinal de la I glesia y una continuidad en las formas de representación plástica basada en la tradición, ${ }^{16}$ de esta forma, cuando los pintores de íconos representan figuras humanas, así como otros elementos de la natural eza, lo hacen con un sentido completamente distinto a l os cánones occidentales derivados de los modelos ital ianos del Renacimiento, en donde el naturalismo es una constante. ${ }^{17}$

Por estos motivos, la presentación sobre el naturalismo está pensada para los estudiantes extranjeros que quieren estudiar el arte occidental, por ello, en la medida de lo posible hemos tratado de realizar una selección de las obras de arte representativas de cada periodo artístico, para que a través de un tema específico, se brinde al al umno un panorama general de la Historia del Arte, y de esa manera, enseñarles conceptos fundamentales para que pueda entender el desarrollo histórico de la pintura novohispana.

Dicha selección, obviamente es subjetiva y por ello no se han incluido muchas obras que podríamos considerar como fundamentales dentro de la historia del arte occi- 
dental, aunque creemos que sí reúne una serie de pinturas particularmente significativas que nos permiten poder explicar periodos y estilos artísticos de una manera adecuada, especial mente a estudiantes que no solamente están aprendiendo un idioma extranjero, sino que en la mayoría de los casosno han tenido un acercamiento previo ala Historia del Arte. En consideración a lo anteriormente expuesto, he dividido esta presentación en tres partes:

1. Visión panorámica de la pintura virreinal en la Nueva España: esta parte consiste en una proyección rápida de aproximadamentetreinta pinturas del periodo virreinal (siglos XVI al XVIII) y tiene como objetivo el mostrar únicamente el tema de estudio del curso. De hecho, es la introducción en donde los alumnos tienen su primer contacto con la pintura novohispana, por lo que hemos puesto especial atención en escoger obras significativas, tanto por su importancia artística, como por su atractivo visual.

2. Visión panorámica de la pintura occidental: através de una muestra de al gunas obras maestras de la pintura occidental, se hace una revisión muy general de la historia de esta manifestación artística, explicando su desarrollo por medio de obras paradigmáticas que permitan al alumno "visualizar" y comprender el desarrollo estilístico de las representaciones pictóricas de Occidente, desde la Prehistoria, hasta las Vanguardias artísticas del siglo XX.

3. Conceptos, temas y problemas de la pintura universal: esta sección toma como punto de partida la selección anterior, para desarrollar después un discurso al terno mediante una presentación interactiva, cuya realización se hizo con baseen los objetivos del curso; para ello, escogimos al gunas obras ilustrativas que nos permitan explicar conceptos, temas y problemas de la pintura universal, de manera que su estudio sirva a los al umnos de ejemplos o puntos de referencia para que posteriormente ellos, al observar otras obras de distintas épocas y tradiciones culturales apliquen dichos conocimientos, y contribuyan con ello activamente en el proceso de enseñanza-aprendizaje, mediante el análisis de una obra artística determinada. plasmar la Apariencia de un paisaje real, sino que las montañas, las rocas, el agua y las plantas, son consideradas como abstracciones formales de una idea [...]. En este sentido es frecuente que el artista no haya visto nunca el paisaje natural que va a representar, sino que lo haya contemplado e interiorizado a través de las obras de los grandes maestros del pasado." Isabel Cervera, Arte y cultura en China. Conceptos, materiales y términos de la $A$ a la Z, Barcelona, Ediciones del Serbal, 1997, (Cultura artística), p.137

16 Con respecto a este tema, cabe mencionar que pese a la existencia de un gran número de "escuelas pictóricas locales” en el arte bizantino, no es muy evidente un desarrollo estilístico desde un punto de vista formal, debido principalmente a la continua utilización de una serie de convencionalismos pictóricos, como el predominio del dorado sobre otros colores, la esquematización de las imágenes, la falta de perspectiva y la subordinación del "paisaje" a las historias representadas. Todo este tipo de convenciones, aunadas a la profunda espiritualidad del cristianismo ortodoxo, son elementos que diferencian de manera muy clara los íconos de las representaciones pictóricas de la Europa católica.

17 Vid. Michel Quenot, El ícono, Bilbao, Desclée de Brouwer, 1990, particularmente el capítulo 2. 


\section{Conclusiones}

A lo largo de este artículo hemos expuesto brevemente uno de los problemas principales que implica enseñar Historia del Arte (concretamentela pintura virreinal en la Nueva España), a estudiantes extranjeros que están aprendiendo español como segunda lengua; dicho problema radica básicamente en la ausencia de referentes culturales - particularmente en el caso de los estudiantes orientales-que permitan al alumno comprender adecuadamente los contenidos del curso.

Por ello, pensamos que el docente además de enfrentar los problemas lingüísticos, debe consi derar también el lugar de origen de sus alumnos, su bagaje cultural y su nivel socioeconómico, ya que los procesos de inferencia que realice el estudiante, básicamente dependerán de la manera en que afrontemos una problemática que como educadores no podemos soslayar. Asimismo, creemos que en el caso de la enseñanza de la Historia del Arte mexicano en general y de la pintura virreinal en particular, es necesaria la realización de nuevos materiales didácticos, basados en una propuesta metodológica que contemple, de manera integral, los contenidos específicos del curso y los problemas relacionados con la enseñanza, así como también las limitantes lingüísticas y culturales delos estudiantes extranjeros que asisten a nuestro Centro. 